\title{
KEPUTUSAN PEMBELIAN DITINJAU KUALITAS PRODUK, LABEL HALAL DAN BRAND IMAGE
}

\author{
Khayrina Nurul Fajritami ${ }^{1}$, Hastho Joko Nur Utomo ${ }^{2 *}$ \\ 1,2 Jurusan Administrasi Bisnis, Universitas Pembangunan Nasional Veteran Yogyakarta \\ *Email Penulis korespondensi: hasthojokonurutomo@gmail.com
}

\begin{abstract}
Abstraksi
Mi instan Samyang pernah menjadi produk yang sangat dicari dan sempat menuai pro kontra karena kehalalannya di Indonesia. Penelitian ini untuk menganalisis pengaruh kualitas produk dan label halal terhadap keputusan pembelian melalui variable brand image. Mahasiswa jurusan Ilmu Administrasi Bisnis yang telah mengkonsumsi mi instan Samyang merupakan populasi penelitian ini. Sampel penelitian terdiri 67 responden, pengumpulan data dengan kuesioner. Analisis data dengan analisis statistik deskriptif dan statistik inferensial (dalam hal ini Structural Equation Modeling menggunakan Smart PLS 3.0). Hasil penelitian menyatakan bahwa label halal berpengaruh signifikan terhadap brand image, berpengaruh tidak signifikan terhadap keputusan pembelian, sedangkan kualitas produk berpengaruh signifikan terhadap brand image, berpengaruh signifikan terhadap keputusan pembelian dan brand image berpengaruh signifikan terhadap keputusan pembelian. Penelitian ini memberikan implikasi manajerial berupa perlunya kebijakan perencanaan produk secara terintegratif yang mencakup kualitas produk, brand image dan labelisasi halal.
\end{abstract}

Kata Kunci: Keputusan Pembelian, Brand Image, Label halal, Kualitas Produk.

\begin{abstract}
Samyang instant noodles were once a highly sought after product and had reaped the pros and cons of being halal in Indonesia. This study is to analyze the effect of product quality and halal label on purchasing decisions through brand image variables. Students majoring in Business Administration who have consumed Samyang instant noodles are the population of this study. The research sample consisted of 67 respondents, collecting data using a questionnaire. Data analysis with descriptive statistical analysis and inferential statistics (in this case Structural Equation Modeling using Smart PLS 3.0). The results of the study state that the halal label has a significant effect on brand image, has no significant effect on purchasing decisions, while product quality has a significant effect on brand image, has a significant effect on purchasing decisions and brand image has a significant effect on purchasing decisions. This study provides managerial implications in the form of the need for an integrated product planning policy that includes product quality, brand image and halal labeling.
\end{abstract}

Keywords: Purchase Decision, Brand Image, Product Quality, Halal Label 


\section{Paradigma: Jurnal Masalah Sosial, Politik, dan Kebijakan \\ http://jurnal.upnyk.ac.id/index.php/paradigma/index P-ISSN: 1410-3133. E-ISSN: Xxxx-xxxx}

\section{Pendahuluan}

Mi instan merupakan salah satu produk yang digemari di Indonesia. Salah satu produk yang beredar di Indonesia yaitu mi instan buldak bokkeummyeon atau lebih familiar disebut sebagai "Samyang" merupakan produk yang sangat populer karena sensasi pedas yang ditawarkan sehingga sempat menjadi tren dikalangan pemuda dengan sebutan "Samyang Challenges" namun produk ini sempat menjadi perdebatan karena terkait dengan kebijakan label halal di Indonesia, BPOM (Badan Pengawasan Obat dan Makanan) menarik 4 produk mi instan asal Korea Selatan dan terdapat 2 produk dengan merek Samyang yang ditarik dari peredaran, meskipun telah dikonfirmasi bahwa mi varian Buldak bokkeummyeon tidak mengandung babi, sampai saat ini masih banyak konsumen yang mencari label halal di kemasan produk. Hal ini terlihat pada marketplace yang menjual mi instan Samyang akan menampilkan logo halal pada gambar produk mereka.

Produk berlabel halal dapat menambah nilai pada brand image produk tersebut (Lutfie et al, 2016; Anggadwita, Dini dan Veland, 2019). Selain itu, label halal bisa mempengaruhi keputusan pembelian (Ahidin et al, 2019; Anggadwita, Dini dan Veland, 2019; Maulidiyah et al, 2019; Simbolon, 2019). Kualitas produk juga bisa mempengaruhi brand image dan keputusan pembelian (Anggadwita, Dini dan Veland (2019), Kurnianto et al (2019) serta Putra dan Nurmahdi (2020). Hasil penelitian Lutfie et al (2016), Ginting (2017) dan Waluya (2019) menyatakan kualitas produk mempengaruhi keputusan pembelian. Brand image dipengaruhi oleh label halal dan kualitas produk; Brand image juga mempengaruhi keputusan pembelian, karena produk dengan brand image yang baik akan dicari meskipun dengan harga yang tinggi (Parameswaran, 2006). Temuan Khairani (2018) dan Waluya (2019) juga menunjukkan bahwa brand image berpengaruh signifikan pada keputusan pembelian.

Penelitian ini menganalisis pengaruh label halal dan kualitas produk terhadap brand image serta dampaknya pada keputusan pembelian mi instan Samyang. Penelitian ini urgen dilakukan seiring dengan meningkatnya kesadaran konsumen untuk membeli produk yang terjamin kehalalannya, bagus kualitasnya, dan juga memiliki brand image yang kuat. Perusahaan yang memperhatikan aspek-aspek tersebut akan memperoleh benefit dan loyalitas konsumen dalam jangka panjang

\section{Kajian Pustaka}

\section{Perilaku Konsumen}

Kotler dan Keller (2008) menyatakan bahwa perilaku konsumen mempelajari individu, kelompok, organisasi, dalam memilih, membeli, menggunakan dan bagaimana barang, jasa ide atau pengalaman untuk memuaskan kebutuhan dan keinginan. Perilaku konsumen merupakan 


\section{Paradigma: Jurnal Masalah Sosial, Politik, dan Kebijakan \\ http://jurnal.upnyk.ac.id/index.php/paradigma/index P-ISSN: 1410-3133. E-ISSN: Xxxx-xxxx}

keputusan konsumen berkaitan dengan akuisisi, konsumsi, dan disposisi barang, jasa, aktivitas, pengalaman, orang, dan gagasan (Hoyer, 2008).

\section{Label Halal}

Sertifikat Halal MUI merupakan fatwa Majelis Ulama Indonesia yang menyatakan kehalalan suatu produk berdasarkan syari'at Islam. Sertifikat Halal ini menjadi syarat bagi pengusaha untuk mendapatkan ijin pencantuman label halal pada kemasan produk. Tujuan sertifikasi Halal pada obat-obatan, produk pangan, kosmetika dilakukan untuk memberikan kepastian status kehalalan, sehingga bisa menentramkan batin konsumen. Keberlanjutan proses produksi secara halal dijamin oleh produsen dengan diterapkannya Sistem Jaminan Halal (lppommuibanten.org). Labelisasi halal menurut Syahputra (2014), adalah pernyataan kehalalan produk yang tertera pada kemasan yang menunjukkan bahwa produk telah memiliki sertifikat halal dari MUI dan telah melalui rangkaian proses untuk memperoleh sertifikat halal yang dilakukan oleh Lembaga Pengkajian Pangan, Obat-obatan, dan Kosmetika Majelis Ulama Indonesia (LPPOMMUI).

\section{Kualitas Produk}

Kualitas merupakan alat pemosisian pemasar, sehingga berdampak langsung pada kinerja produk. Kualitas berkaitan erat dengan kepuasan pelanggan. Kualitas dapat diartikan secara sempit dengan "terbebas dari cacat". Sebagian besar perusahaan mendefinisikan kualitas dalam konteks kepuasan pelanggan (Kotler et al, 2005).

Kualitas produk merupakan kemampuan produk dalam melakukan fungsinya yang mencakup daya tahan produk, keandalan, presisi, kemudahan pengoperasian dan perbaikan. Pengukuran kualitas dari segi persepsi pembeli. Kualitas produk berarti kualitas yang berkesesuaian dan terbebas dari cacat. Kualitas secara konsisten mencerminkan tingkat kinerja yang ditargetkan (Kotler et al, 2005).

\section{Brand Image}

Menurut Kotler dan Keller, Brand atau merek (2008) adalah produk atau jasa yang dimensinya membedakan merek tersebut dengan beberapa produk atau jasa lainnya. Brand image merupakan gambaran asosiasi dan keyakinan konsumen terhadap merek tertentu (Ambadar dalam Khairani, 2017). Brand image yang baik membuat konsumen memilih suatu merek dibandingkan dengan merek yang lain. Hal ini terlihat dari kesediaan pelanggan membayar lebih tinggi. Nilai brand equity bagi konsumen dapat memberikan nilai dalam memperkuat pemahaman mereka akan proses informasi, memupuk rasa percaya diri dan meningkatkan kepuasan. Brand dengan brand equity yang kuat adalah brand yang mampu bertahan, bersaing dan menjadi penguasa di pasar. 


\section{Paradigma: Jurnal Masalah Sosial, Politik, dan Kebijakan \\ http://jurnal.upnyk.ac.id/index.php/paradigma/index P-ISSN: 1410-3133. E-ISSN: Xxxx-xxxx}

Semakin kuat brand equity maka akan semakin kuat pula daya tarik untuk mengkonsumsi merek tersebut secara setia dan memberikan keuntungan bagi pihak perusahaan (Winarto, 2011).

\section{Keputusan Pembelian}

Keputusan pembelian menurut Kotler et al (2005) adalah tahapan dalam proses keputusan pembelian dimana konsumen secara nyata membeli produk. Pelanggan memutuskan produk yang akan dibeli berdasarkan persepsi pelanggan terhadap kemampuan produk dalam memenuhi kebutuhannya. Proses keputusan konsumen mengarah pada pilihan konsumen. Pilihan pertama konsumen ketika membuat keputusan adalah memutuskan apakah akan melakukan pembelian atau tidak, ini terjadi karena tidak jarang konsumen menunda atau bahkan tidak jadi melakukan pembelian produk (Tjiptono dan Diana, 2019).

\section{Label Halal dan Brand Image}

Produk yang di kemasannya telah berlabel halal secara emosional akan mempengaruhi konsumen bahwa produk tersebut aman dan bebas dari resiko yang kemudian mempengaruhinya dalam proses keputusan pembelian (Elliott, 2015). Lutfie et al (2016) menyatakan bahwa produk yang telah memiliki label halal pada kemasannya dapat menambah nilai pada brand image dari produk tersebut. Hasil penelitian Anggadwita, Dini dan Veland (2019) menunjukkan bahwa label halal mempengaruhi nilai brand image produk secara signifikan.

Hipotesis 1. Label halal berpengaruh signifikan terhadap brand image.

\section{Label Halal dan Keputusan Pembelian}

Label halal merupakan faktor yang dipertimbangkan dalam proses keputusan pembelian. Informasi produk yang jelas akan membuat konsumen melakukan pembelian tanpa ragu (Kotler, 2005). Meningkatnya kesadaran masyarakat mengenai label halal berdampak pada keputusan mereka untuk membeli produk dan jasa (Anggadwita, Dini dan Veland, 2019). Maulidiyah et al (2019) dan Simbolon (2019) juga menyatakan bahwa label halal mempengaruhi keputusan pembelian konsumen.

Hipotesis 2. Label halal berpengaruh signifikan terhadap keputusan pembelian.

\section{Kualitas Produk dan Brand Image}

Produk berkualitas baik akan menghasilkan kepuasan dalam penggunaanya yang kemudian mempengaruhi perspektif konsumen pada brand image. Di saat konsumen merasa puas dengan 


\section{Paradigma: Jurnal Masalah Sosial, Politik, dan Kebijakan \\ http://jurnal.upnyk.ac.id/index.php/paradigma/index P-ISSN: 1410-3133. E-ISSN: Xxxx-xxxx}

kualitas produk yang telah digunakan, konsumen akan menanyakan tentang brand dari produk, maka dari itu, brand harus menawarkan manfaat fungsional yang lebih baik dari kompetitornya agar brand tersebut memiliki image yang baik (Parameswaran, 2006). Produk dengan kualitas yang baik dapat meningkatkan nilai pada brand image dari produk tersebut Anggadwita, Dini dan Veland (2019), Putra dan Nurmahdi (2020) menyatakan bahwa konsumen menginginkan produk dengan kualitas yang terbaik, apabila kualitas suatu produk baik, maka brand image-nya meningkat.

Hipotesis 3. Kualitas Produk berpengaruh secara signifikan terhadap brand image.

Kualitas Produk dan Keputusan Pembelian

Kualitas produk merupakan salah satu penentu posisi utama pemasar karena akan berdampak langsung pada kinerja produk. Keputusan pembelian sangat dipengaruhi oleh kualitas produk karena produk yang berkualitas akan dicari oleh konsumen (Kotler, 2005). Lutfie et al (2016) menjelaskan bahwa kualitas produk merupakan faktor yang mempengaruhi keputusan pembelian. Produk dengan kualitas yang baik akan berpengaruh pada keputusan pembelian (Ginting, 2017).

Hipotesis 4. Kualitas produk berpengaruh signifikan terhadap keputusan pembelian.

\section{Brand Image dan Keputusan Pembelian}

Brand image yang bagus bagi suatu produk akan membuat konsumen bersedia membeli suatu produk walaupun harganya lebih tinggi (Parameswaran, 2006). Brand image bisa mempengaruhi keputusan pembelian karena ekspektasi konsumen terhadap suatu merek telah terpenuhi (Waluya, 2019). Produk dengan brand image yang bagus akan berpengaruh terhadap keputusan pembelian (Anggadwita, Dini dan Veland, 2019).

Hipotesis 5. Brand image berpengaruh secara signifikan terhadap keputusan pembelian.

\section{Metode Penelitian}

\section{Pengambilan data dan sampel}

Data penelitian dikumpulkan dari kuesioner online yang dibagikan kepada responden melalui google forms. Populasi penelitian ini 80 responden. Berdasarkan perhitungan menggunakan rumus Slovin didapatkan sampel sebanyak 67 responden. Berdasarkan data tersebut, dari 80 responden dipilih secara acak (Simple random sampling) menggunakan Microsoft excel sejumlah 67 


\section{Paradigma: Jurnal Masalah Sosial, Politik, dan Kebijakan \\ http://jurnal.upnyk.ac.id/index.php/paradigma/index P-ISSN: 1410-3133. E-ISSN: Xxxx-xxxx}

responden Sampel penelitian ini mahasiswa Administrasi Bisnis UPN "Veteran" Yogyakarta angkatan 2016-2020 dan pernah mengkonsumsi mi instan Samyang.

\section{Instrumen dan analisis data}

Instrumen pengumpulan data berupa kuesioner yang berisi sekumpulan pertanyaan mengenai data responden dan pernyataan yang berkaitan item variabel penelitian. Variabel Label halal diukur dengan tiga dimensi (Perhatian konsumen terhadap keberadaan label halal, penempatan label halal pada kemasan dan kepastian bahwa produk aman) yang mengacu pada (Anggadwita, Dini dan Veland, 2019). Kualitas produk diukur dengan enam dimensi (Jaminan, kinerja, keandalan, kesesuaian, daya tahan dan estetika) yang diadaptasi dari (Anggadwita, Dini dan Veland, 2019). Brand image diukur dengan tiga dimensi (Kekuatan brand, keunggulan brand dan keunikan brand) mengacu pada (Anggadwita, Dini dan Veland, 2019). Keputusan pembelian diukur dengan menggunakan indikator yang dikembangkan oleh Mahliza (2020). Uji validitas dan reliabilitas tahap pertama dilakukan pada 30 responden pertama dengan alat bantu SPSS, Indikator yang valid kemudian akan dilanjutkan kepada responden lainnya dan dianalisis menggunakan SmartPLS.

\section{Hasil}

\section{Hasil Uji Validitas dan reliabilitas}

Hasil perhitungan terlihat pada Tabel 1, berdasarkan tabel terlihat bahwa nilai koefisien korelasi tiap item lebih dari 0,3 sehingga dinyatakan valid dan nilai Cronbach alpha pada setiap variabel melebihi 0,6 sehingga dinyatakan reliabel.

\section{Karakteristik Responden}

Karakteristik responden terlihat pada tabel 2. Berdasarkan tabel, terlihat bahwa mayoritas responden merupakan mahasiswa angkatan 2017 (32,8\%), seluruh responden beragama Islam, mayoritas merupakan perempuan $(76,1 \%)$, mayoritas responden melakukan pembelian lebih dari 1 bulan sekali (77,6\%), mayoritas responden mengkonsumsi lebih dari 1 bulan sekali $(76,1 \%)$ dan mayoritas responden melakukan pembelian di toko retail $(83,6 \%)$.

\section{Analisis Inferensial \\ Pengujian Model Pengukuran (outer model) \\ Hasil Uji Validitas \\ Validitas Konvergen}

Hasil perhitungan terlihat pada Tabel 3, item dikatakan valid secara konvergen bila nilai loading factors pada outer loadings tiap indikator lebih dari 0,60. Bila terdapat indikator dengan nilai dibawah 0,60 maka indikator tersebut harus dihapus Ghozali (2014). Pada pengujian ini terdapat beberapa item yang tidak valid, sehingga harus dihapus. Tabel 3 menunjukkan item dengan nilai loading factors lebih dari 0,6 dan dinyatakan valid secara konvergen. 


\section{Paradigma: Jurnal Masalah Sosial, Politik, dan Kebijakan \\ http://jurnal.upnyk.ac.id/index.php/paradigma/index P-ISSN: 1410-3133. E-ISSN: Xxxx-xxxx}

\section{Validitas Diskriminan}

Data yang telah memenuhi validitas konvergen kemudian dilanjutkan dengan uji validitas diskriminan, data dikatakan valid secara diskriminan apabila nilai Average Variance Extracted lebih dari 0,50 dan nilai korelasi suatu kostruk lebih besar daripada nilai konstruknya dengan konstruk lain pada Fornell Larcker Criterion. Tabel 4 dan 5 menunjukkan bahwa data valid secara diskriminan dan dapat dilanjutkan pada pengujian reliabilitas.

Hasil Uji Reliabilitas

Uji reliabilitas pada SmartPLS dilihat pada Cronbach's Alpha dan Composite Reliability, suatu variabel dikatakan reliabel jika nilai Cronbach's Alpha dan Composite Reliability lebih dari 0,70. Tabel 6 menunjukkan bahwa data memenuhi syarat dan dapat dikatakan reliabel.

\section{Pengujian Model Struktural (inner model) \\ Goodness-fit Model (R-Square)}

Uji pengaruh merupakan tahap awal dalam menilai model struktural PLS, hasil uji dapat dilakukan dengan melihat nilai R-Squares yang merupakan uji goodness-fit model. Tabel 7 menujukkan bahwa nilai R-Square untuk variabel Brand Image sebesar 0,625 yang berarti bahwa variabel Brand Image dapat dijelaskan oleh variabel Label Halal dan Kualitas Produk sebesar 62,5\% sedangkan 37,5\% dijelaskan oleh variabel lain diluar yang diteliti. Nilai R-Square variabel Keputusan Pembelian sebesar 0,501 yang berarti bahwa variabel Keputusan Pembelian dapat dijelaskan oleh variabel Label Halal, Kualitas Produk dan Brand Image sebesar 50,1\% sedangkan 49,9\% dijelaskan oleh variabel lain diluar yang diteliti.

\section{Uji Hipotesis}

Hipotesis 1 menyatakan bahwa label halal berpengaruh signifikan terhadap brand image. Hasil uji (tabel 8) menunjukkan nilai t hitung sebesar 3,073 lebih besar dari pada 1,960 sehingga dapat disimpulkan bahwa hipotesis diterima, hal ini menunjukkan bahwa label halal berpengaruh signifikan terhadap brand image.

Hipotesis 2 menyatakan bahwa label halal berpengaruh signifikan terhadap keputusan pembelian. Hasil uji (tabel 8) menunjukkan nilai t hitung sebesar 1,565 kurang dari 1,960 sehingga dapat disimpulkan bahwa hipotesis ditolak, hal ini menunjukkan bahwa label halal tidak berpengaruh signifikan terhadap keputusan pembelian.

Hipotesis 3 menyatakan bahwa kualitas produk berpengaruh signifikan terhadap brand image. Hasil uji (tabel 8) menunjukkan nilai t hitung sebesar 9,190 lebih dari 1,960 sehingga dapat disimpulkan bahwa hipotesis diterima, hal ini menunjukkan bahwa kualitas produk berpengaruh signifikan terhadap brand image.

Hipotesis 4 menyatakan bahwa kualitas produk berpengaruh signifikan terhadap keputusan pembelian. Hasil uji (tabel 8) menunjukkan nilai t hitung sebesar 3,692 lebih dari 1,960 sehingga dapat disimpulkan bahwa hipotesis diterima, hal ini menunjukkan bahwa kualitas produk berpengaruh signifikan terhadap keputusan pembelian. 


\section{Paradigma: Jurnal Masalah Sosial, Politik, dan Kebijakan}

http://jurnal.upnyk.ac.id/index.php/paradigma/index P-ISSN: 1410-3133. E-ISSN: Xxxx-Xxxx

Hipotesis 5 menyatakan bahwa brand image berpengaruh signifikan terhadap keputusan pembelian. Hasil uji (tabel 8) menunjukkan nilai t hitung sebesar 1,965 lebih dari 1,960 sehingga dapat disimpulkan bahwa brand image berpengaruh signifikan terhadap keputusan pembelian.

Tabel 1. Hasil Uji Validitas dan Reliabilitas

\begin{tabular}{|c|c|c|c|}
\hline Variabel & Item/Pernyataan & $\begin{array}{c}\text { Koefisien } \\
\text { Korelasi }\end{array}$ & $\begin{array}{l}\text { Cronbach } \\
\text { Alpha }\end{array}$ \\
\hline \multirow[t]{9}{*}{ Label halal } & $\begin{array}{l}\text { X1.1 Perhatian label halal pada kemasan mi instan } \\
\text { Samvang }\end{array}$ & $.784^{* *}$ & \multirow[t]{9}{*}{0,844} \\
\hline & $\begin{array}{l}\text { X1.2 Perhatian keterangan label halal di kemasan } \\
\text { mi instan Samyang. }\end{array}$ & $.773^{* *}$ & \\
\hline & $\begin{array}{l}\text { X1.3 Mengetahui maksud dari adanya label halal } \\
\text { pada kemasan. }\end{array}$ & $.642^{* *}$ & \\
\hline & $\begin{array}{l}\text { X1.4 Keyakinan adanya label halal pada kemasan } \\
\text { sebagai jaminan halal. }\end{array}$ & $.517^{* *}$ & \\
\hline & $\begin{array}{l}\text { X1.5 Keberadaan label halal pada kemasan mudah } \\
\text { ditemukan }\end{array}$ & $.743^{* *}$ & \\
\hline & $\begin{array}{l}\text { X1.6 Pencantuman label halal pada kemasan sudah } \\
\text { ideal. }\end{array}$ & $.727^{* *}$ & \\
\hline & $\begin{array}{l}\text { X1.7 Mempertimbangkan adanya label halal } \\
\text { sebelum membeli. }\end{array}$ & $.806^{* *}$ & \\
\hline & $\begin{array}{l}\text { X1.8 Hanya melakukan pembelian pada produk } \\
\text { dengan label halal. }\end{array}$ & $.496^{* *}$ & \\
\hline & $\begin{array}{l}\text { X1.10 Kesadaran akan pentingnya pencantuman } \\
\text { label halal dalam kemasan }\end{array}$ & $.423^{*}$ & \\
\hline \multirow[t]{14}{*}{$\begin{array}{l}\text { Kualitas } \\
\text { Produk }\end{array}$} & $\begin{array}{l}\text { X2.1 Percaya bahwa mi instan Samyang memiliki } \\
\text { kualitas yang baik. }\end{array}$ & $.471^{* *}$ & \multirow[t]{14}{*}{0,889} \\
\hline & $\begin{array}{l}\text { X2.2 Percaya bahwa membeli mi instan Samyang } \\
\text { tidak rugi. }\end{array}$ & $.709^{* *}$ & \\
\hline & $\begin{array}{l}\text { X2.3 Mi instan Samyang bermanfaat bagi } \\
\text { pemenuhan kebutuhan makan. }\end{array}$ & $.499^{* *}$ & \\
\hline & $\begin{array}{l}\text { X2.4 Mi instan Samyang tidak memberikan efek } \\
\text { negatif bagi tubuh. }\end{array}$ & $.729^{* *}$ & \\
\hline & $\begin{array}{l}\text { X2.5 Mi instan Samyang sesuai dengan standar } \\
\text { yang dijanjikan. }\end{array}$ & $.768^{* *}$ & \\
\hline & $\begin{array}{l}\text { X2.6 Mi instan Samyang memiliki kualitas yang } \\
\text { konsisten. }\end{array}$ & $.541^{* *}$ & \\
\hline & $\begin{array}{l}\text { X2.7 Kualitas mi instan Samyang mampu } \\
\text { memenuhi harapan. }\end{array}$ & $.718^{* *}$ & \\
\hline & $\begin{array}{l}\text { X2.8 Cita rasa mi instan Samyang sesuai dengan } \\
\text { yang diharapkan. }\end{array}$ & $.710^{* *}$ & \\
\hline & $\begin{array}{l}\text { X2.9 Kemasan mi instan samyang tidak mudah } \\
\text { rusak. }\end{array}$ & $.754^{* *}$ & \\
\hline & $\begin{array}{l}\text { X2.10 Kemasan mi instan Samyang cukup untuk } \\
\text { melindungi produk didalamnya. }\end{array}$ & $.673^{* *}$ & \\
\hline & X2.11 Tekstur mi instan Samyang kenyal & $.721^{* *}$ & \\
\hline & X2.12 Bentuk mi instan Samyang menarik. & $.615^{* *}$ & \\
\hline & X2.13 Kemasan mi instan Samyang menarik. & $.678^{* *}$ & \\
\hline & X2.14 Kemasan mi instan Samyang unik. & $.454^{*}$ & \\
\hline
\end{tabular}




\section{Paradigma: Jurnal Masalah Sosial, Politik, dan Kebijakan}

http://jurnal.upnyk.ac.id/index.php/paradigma/index P-ISSN: 1410-3133. E-ISSN: Xxxx-xxxx

\begin{tabular}{|c|c|c|c|}
\hline Variabel & Item/Pernyataan & $\begin{array}{l}\text { Koefisien } \\
\text { Korelasi }\end{array}$ & $\begin{array}{l}\text { Cronbach } \\
\text { Alpha }\end{array}$ \\
\hline \multirow[t]{15}{*}{$\begin{array}{l}\text { Brand } \\
\text { Image }\end{array}$} & $\begin{array}{l}\text { Y1.1 Logo mi instan Samyang identik dengan } \\
\text { produknya. }\end{array}$ & $.657^{* *}$ & \multirow[t]{15}{*}{0,932} \\
\hline & $\begin{array}{l}\text { Y1.2 Logo mi instan Samyang mudah } \\
\text { dikenali. }\end{array}$ & $.774^{* *}$ & \\
\hline & $\begin{array}{l}\text { Y1.3 Mi instan Samyang adalah produk yang } \\
\text { halal. }\end{array}$ & $.692^{* *}$ & \\
\hline & $\begin{array}{l}\text { Y1.4 Mi instan Samyang dicitrakan sebagai } \\
\text { produk halal. }\end{array}$ & $.615^{* *}$ & \\
\hline & $\begin{array}{l}\text { Y1.5 Mi instan Samyang memiliki citra } \\
\text { produk yang berkualitas }\end{array}$ & $.821^{* *}$ & \\
\hline & $\begin{array}{l}\text { Y1.6 Mi instan Samyang dicitrakan sebagai } \\
\text { produk yang berkualitas. }\end{array}$ & $.835^{* *}$ & \\
\hline & $\begin{array}{l}\text { Y1.7 Mi instan Samyang memiliki harga yang } \\
\text { terjangkau. }\end{array}$ & $.495^{* *}$ & \\
\hline & Y1.9 Mi instan Samyang tersedia di pasar. & $.793^{* *}$ & \\
\hline & $\begin{array}{l}\text { Y1.10 Mi instan Samyang mudah untuk } \\
\text { dicari. }\end{array}$ & $.725^{* *}$ & \\
\hline & Y1.11 Brand "Samyang" mudah diucapkan. & $.749^{* *}$ & \\
\hline & $\begin{array}{l}\text { Y1.12 Brand "Samyang" tidak asing untuk } \\
\text { diucapkan }\end{array}$ & $.751^{* *}$ & \\
\hline & $\begin{array}{l}\text { Y1.13 Brand "Samyang" mudah untuk Y1.1 } \\
\text { diingat. }\end{array}$ & $.805^{* *}$ & \\
\hline & $\begin{array}{l}\text { Y1.14 Brand "Samyang" merupakan top of } \\
\text { mind. }\end{array}$ & $.667^{* *}$ & \\
\hline & $\begin{array}{l}\text { Y1.15 Brand "Samyang" memiliki nilai } \\
\text { tersendiri. }\end{array}$ & $.795^{* *}$ & \\
\hline & $\begin{array}{l}\text { Y1.16 Brand "samyang" selalu ada dibenak } \\
\text { konsumen. }\end{array}$ & $.615^{* *}$ & \\
\hline \multirow[t]{6}{*}{$\begin{array}{l}\text { Keputusan } \\
\text { Pembelian }\end{array}$} & $\begin{array}{l}\text { Y2.1 Kemantapan dalam melakukan } \\
\text { pembelian. }\end{array}$ & $.760^{* *}$ & \multirow[t]{6}{*}{0,898} \\
\hline & Y2.2 Persediaan mi instan Samyang. & $.643^{* *}$ & \\
\hline & $\begin{array}{l}\text { Y2.3 Memiliki keinginan untuk melakukan } \\
\text { pembelian kembali. }\end{array}$ & $.898^{* *}$ & \\
\hline & $\begin{array}{l}\text { Y2.4 Mi instan Samyang adalah pilihan } \\
\text { terbaik di waktu yang akan datang. }\end{array}$ & $.832^{* *}$ & \\
\hline & $\begin{array}{l}\text { Y2.5 Produk mi instan samyang sesuai dengan } \\
\text { harapan. }\end{array}$ & $.889^{* *}$ & \\
\hline & $\begin{array}{l}\text { Y2.6 Produk mi instan Samyang mampu } \\
\text { memenuhi keinginan. }\end{array}$ & $.869^{* *}$ & \\
\hline
\end{tabular}

Sumber: Data primer diolah tahun 2020 


\section{Paradigma: Jurnal Masalah Sosial, Politik, dan Kebijakan}

http://jurnal.upnyk.ac.id/index.php/paradigma/index

P-ISSN: 1410-3133. E-ISSN: Xxxx-Xxxx

Tabel 2. Karakteristik Responden

\begin{tabular}{|c|l|c|}
\hline \multirow{3}{*}{ Angkatan } & 2016 & $4,5 \%$ \\
\cline { 2 - 3 } & 2017 & $32,8 \%$ \\
\cline { 2 - 3 } & 2018 & $23,9 \%$ \\
\cline { 2 - 3 } & 2019 & $14,9 \%$ \\
\cline { 2 - 3 } & 2020 & $23,9 \%$ \\
\hline Agama & Islam & $100 \%$ \\
\hline Jenis Kelamin & Laki-laki & $23,9 \%$ \\
\cline { 2 - 3 } & Perempuan & $76,1 \%$ \\
\hline \multirow{2}{*}{ Frekuensi Pembelian } & 1 Pekan Sekali & $4,5 \%$ \\
\cline { 2 - 3 } & 1 Bulan Sekali & $17,9 \%$ \\
\cline { 2 - 3 } & Lebih dari 1 bulan sekali & $77,6 \%$ \\
\hline \multirow{2}{*}{ Frekuensi Konsumsi } & 1 Pekan Sekali & $6 \%$ \\
\cline { 2 - 3 } & 1 Bulan Sekali & $17,9 \%$ \\
\cline { 2 - 3 } & Lebih dari 1 bulan sekali & $76,1 \%$ \\
\hline Tempat Pembelian & Toko retail & $83,6 \%$ \\
\cline { 2 - 3 } & Marketplace & $16,4 \%$ \\
\hline
\end{tabular}

Sumber: Data primer diolah tahun 2020

Tabel 3. Hasil Uji Validitas Konvergen

\begin{tabular}{|c|c|c|}
\hline Variabel & Item/Pernyataan & $\begin{array}{l}\text { Loading } \\
\text { Factors }\end{array}$ \\
\hline \multirow{7}{*}{$\begin{array}{l}\text { Label } \\
\text { Halal }\end{array}$} & X1.1 Perhatian label halal pada kemasan mi instan Samyang. & 0.795 \\
\hline & $\begin{array}{l}\text { X1.2 Perhatian keterangan label halal di kemasan mi instan } \\
\text { Samyang. }\end{array}$ & 0.800 \\
\hline & X1.3 Mengetahui maksud dari adanya label halal pada kemasan. & 0.845 \\
\hline & $\begin{array}{l}\text { X1.4 Keyakinan adanya label halal pada kemasan sebagai jaminan } \\
\text { halal. }\end{array}$ & 0.748 \\
\hline & X1.5 Keberadaan label halal pada kemasan mudah ditemukan & 0.638 \\
\hline & X1.7 Mempertimbangkan adanya label halal sebelum membeli. & 0.675 \\
\hline & $\begin{array}{l}\text { X1.10 Kesadaran akan pentingnya pencantuman label halal dalam } \\
\text { kemasan }\end{array}$ & 0.622 \\
\hline \multirow{11}{*}{$\begin{array}{l}\text { Kualitas } \\
\text { Produk }\end{array}$} & X2.2 Percaya bahwa membeli mi instan Samyang tidak rugi. & 0.756 \\
\hline & X2.5 Mi instan Samyang sesuai dengan standar yang dijanjikan. & 0.748 \\
\hline & X2.6 Mi instan Samyang memiliki kualitas yang konsisten. & 0.650 \\
\hline & X2.7 Kualitas mi instan Samyang mampu memenuhi harapan. & 0.778 \\
\hline & X2.8 Cita rasa mi instan Samyang sesuai dengan yang diharapkan. & 0.772 \\
\hline & X2.9 Kemasan mi instan samyang tidak mudah rusak. & 0.775 \\
\hline & $\begin{array}{l}\text { X2.10 Kemasan mi instan Samyang cukup untuk melindungi } \\
\text { produk didalamnya. }\end{array}$ & 0.707 \\
\hline & X2.11 Tekstur mi instan Samyang kenyal & 0.668 \\
\hline & X2.12 Bentuk mi instan Samyang menarik. & 0.648 \\
\hline & X2.13 Kemasan mi instan Samyang menarik. & 0.675 \\
\hline & X2.14 Kemasan mi instan Samyang unik. & 0.613 \\
\hline
\end{tabular}

Sumber: Data primer diolah tahun 2020 


\section{Paradigma: Jurnal Masalah Sosial, Politik, dan Kebijakan}

http://jurnal.upnyk.ac.id/index.php/paradigma/index P-ISSN: 1410-3133. E-ISSN: Xxxx-Xxxx

\begin{tabular}{|l|l|c|}
\hline Variabel & \multicolumn{1}{|c|}{ Item/Pernyataan } & $\begin{array}{c}\text { Loading } \\
\text { Factors }\end{array}$ \\
\hline \multirow{4}{*}{$\begin{array}{l}\text { Brand } \\
\text { Image }\end{array}$} & Y1.4 Mi instan Samyang dicitrakan sebagai produk halal. & 0.759 \\
\cline { 2 - 3 } & Y1.5 Mi instan Samyang memiliki citra produk yang berkualitas & 0.812 \\
\cline { 2 - 3 } & $\begin{array}{l}\text { Y1.6 Mi instan Samyang dicitrakan sebagai produk yang } \\
\text { berkualitas. }\end{array}$ & 0.835 \\
\cline { 2 - 3 } & Y1.9 Mi instan Samyang tersedia di pasar. & 0.712 \\
\cline { 2 - 3 } & Y1.10 Mi instan Samyang mudah untuk dicari. & 0.749 \\
\cline { 2 - 3 } & Y1.11 Brand "Samyang" mudah diucapkan. & 0.761 \\
\cline { 2 - 3 } & Y1.12 Brand "Samyang" tidak asing untuk diucapkan & 0.823 \\
\cline { 2 - 3 } & Y1.13 Brand "Samyang" mudah untuk Y1.1 diingat. & 0.807 \\
\cline { 2 - 3 } & Y1.14 Brand "Samyang" merupakan top of mind. & 0.747 \\
\cline { 2 - 3 } & Y1.15 Brand "Samyang" memiliki nilai tersendiri. & 0.829 \\
\hline \multirow{7}{*}{ Keputusan } & Y2.1 Kemantapan dalam melakukan pembelian. & 0.839 \\
\cline { 2 - 3 } & Y2.3 Memiliki keinginan untuk melakukan pembelian kembali. & 0.795 \\
\cline { 2 - 3 } & Y2.4 Mi instan Samyang adalah pilihan terbaik di waktu yang & 0.799 \\
& \begin{tabular}{l} 
akan datang. \\
\cline { 2 - 3 }
\end{tabular} & 0.922 \\
\cline { 2 - 3 } & Y2.5 Produk mi instan samyang sesuai dengan harapan. & 0.904 \\
\hline
\end{tabular}

Sumber: Data primer diolah tahun 2020

Tabel 4. Nilai Average Variant Extracted (AVE)

\begin{tabular}{|c|c|}
\hline & $\begin{array}{c}\text { Average Variant Extracted } \\
\text { (AVE) }\end{array}$ \\
\hline Label Halal & 0,542 \\
\hline Kualitas Produk & 0,505 \\
\hline Brand Image & 0,615 \\
\hline Keputusan Pembelian & 0,729 \\
\hline
\end{tabular}

Sumber: Data primer diolah tahun 2020

Tabel 5. Fornell Larcker Criterion

\begin{tabular}{|c|c|c|c|c|}
\hline & $\begin{array}{c}\text { Label } \\
\text { Halal }\end{array}$ & $\begin{array}{c}\text { Kualitas } \\
\text { Produk }\end{array}$ & $\begin{array}{c}\text { Brand } \\
\text { Image }\end{array}$ & $\begin{array}{c}\text { Keputusa } \\
\mathrm{n} \\
\text { Pembelia } \\
\mathrm{n}\end{array}$ \\
\hline Label Halal & 0,736 & & & \\
\hline Kualitas Produk & 0,368 & 0,737 & & \\
\hline Brand Image & 0,516 & 0,729 & 0,784 & \\
\hline $\begin{array}{c}\text { Keputusan } \\
\text { Pembelian }\end{array}$ & 0,185 & 0,683 & 0,607 & 0,853 \\
\hline
\end{tabular}

Sumber: Data primer diolah tahun 2020 


\section{Paradigma: Jurnal Masalah Sosial, Politik, dan Kebijakan}

http://jurnal.upnyk.ac.id/index.php/paradigma/index P-ISSN: 1410-3133. E-ISSN: Xxxx-Xxxx

Tabel 6. Hasil Uji Reliabilitas

\begin{tabular}{|c|c|c|}
\hline & Cronbach's Alpha & $\begin{array}{c}\text { Composite } \\
\text { Reliability }\end{array}$ \\
\hline Label Halal & 0,864 & 0,891 \\
\hline Kualitas Produk & 0,901 & 0,918 \\
\hline Brand Image & 0,931 & 0,941 \\
\hline $\begin{array}{c}\text { Keputusan } \\
\text { Pembelian }\end{array}$ & 0,907 & 0,930 \\
\hline
\end{tabular}

Sumber: Data primer diolah tahun 2020

Tabel 7. Hasil Uji goodness-fit model

\begin{tabular}{|c|c|c|c|}
\hline Variabel & $\begin{array}{c}\text { Original } \\
\text { Sample }\end{array}$ & t Statistics & P Values \\
\hline Brand Image & 0,625 & 9,026 & 0,000 \\
\hline $\begin{array}{c}\text { Keputusan } \\
\text { Pembelian }\end{array}$ & 0,501 & 6,468 & 0,000 \\
\hline
\end{tabular}

Sumber: Data primer diolah tahun 2020

Tabel 8. Hasil Uji Hipotesis

\begin{tabular}{|l|c|c|c|c|}
\hline \multicolumn{1}{|c|}{ Variabel } & $\begin{array}{c}\text { Original } \\
\text { Sample }\end{array}$ & $\begin{array}{c}t \\
\text { Statistic } \\
s\end{array}$ & Deskripsi & Hasil \\
\hline $\begin{array}{l}\text { Label Halal Terhadap } \\
\text { Brand Image }\end{array}$ & 0,284 & 3,073 & Signifikan & Diterima \\
\hline $\begin{array}{l}\text { Label Halal Terhadap } \\
\text { Keputusan Pembelian }\end{array}$ & $-0,161$ & 1,565 & $\begin{array}{c}\text { Tidak } \\
\text { Signifikan }\end{array}$ & Ditolak \\
\hline $\begin{array}{l}\text { Kualitas Produk Terhadap } \\
\text { Brand Image }\end{array}$ & 0,642 & 9,190 & Signifikan & Diterima \\
\hline $\begin{array}{l}\text { Kualitas Produk Terhadap } \\
\text { Keputusan Pembelian }\end{array}$ & 0,505 & 3,692 & Signifikan & Diterima \\
\hline $\begin{array}{l}\text { Brand Image Terhadap } \\
\text { Keputusan Pembelian }\end{array}$ & 0,311 & 1,965 & Signifikan & Diterima \\
\hline
\end{tabular}

Sumber: Data primer diolah tahun 2020 


\section{Paradigma: Jurnal Masalah Sosial, Politik, dan Kebijakan}

http://jurnal.upnyk.ac.id/index.php/paradigma/index P-ISSN: 1410-3133. E-ISSN: Xxxx-xxxx

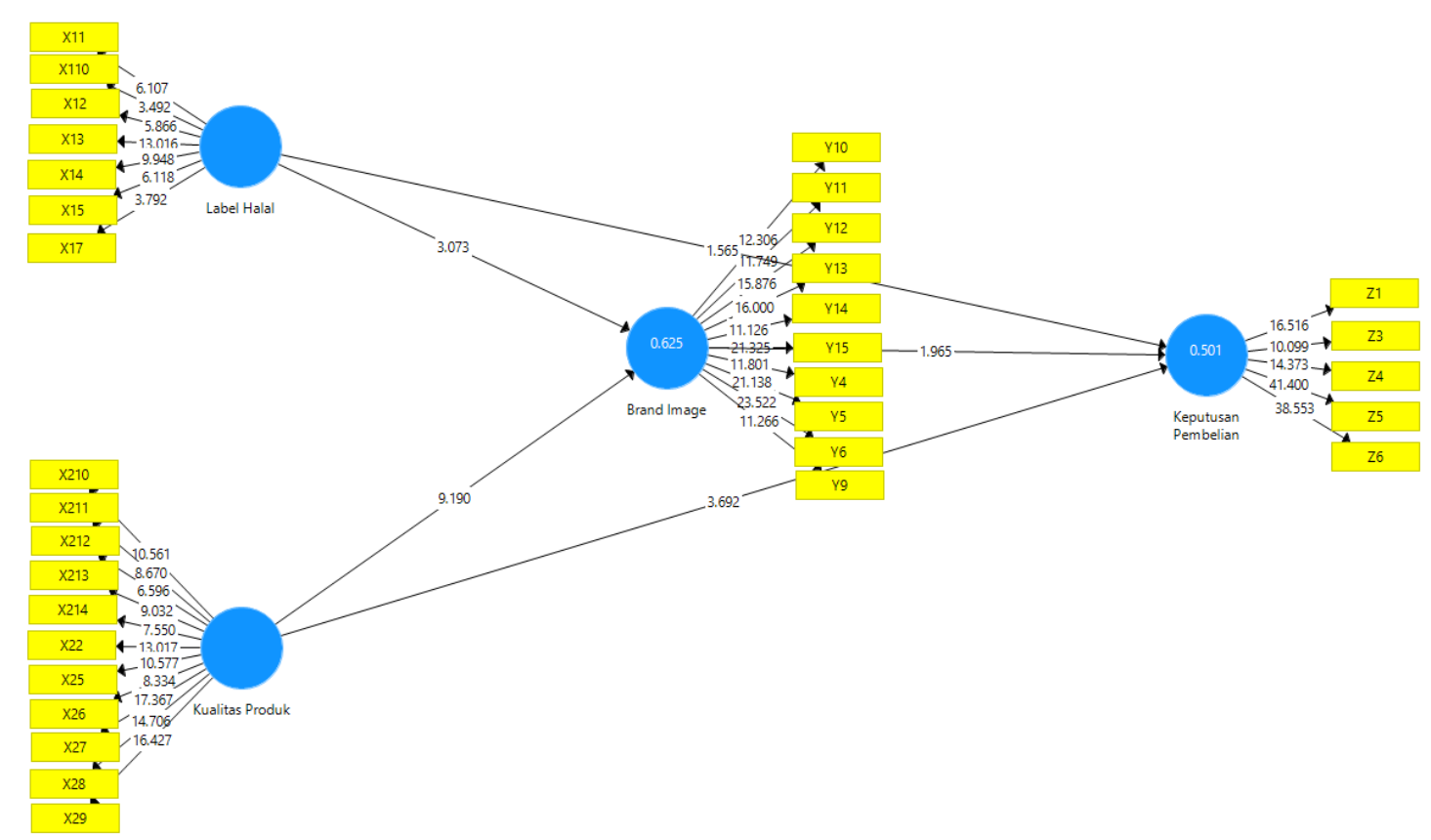

Sumber: Data primer diolah tahun 2020

\section{Gambar 1. Hasil Uji dengan SmartPLS}

\section{Hasil dan Pembahasan}

\section{Pengaruh Label Halal Terhadap Brand Image}

Hasil uji hipotesis 1 menunjukkan bahwa label halal berpengaruh signifikan terhadap brand image. Hal ini berarti bahwa penelitian ini mendukung teori Elliott (2015) yang menyatakan pencantuman label halal pada kemasan dapat mempengaruhi konsumen secara emosional dan membentuk brand image yang baik di benak pelanggan. Hasil hipotesis ini juga mendukung hasil penelitian terdahulu oleh Lutfie et al (2016) dan Anggadwita (2019) bahwa label halal merupakan faktor yang membentuk atau menambah nilai brand image produk. Hal ini menunjukkan bahwa adanya label halal pada kemasan dapat meningkatkan brand image dari produk mi instan Samyang.

\section{Pengaruh Label Halal Terhadap Keputusan Pembelian}

Hasil uji hipotesis 2 menunjukan bahwa label halal tidak berpengaruh signifikan terhadap keputusan pembelian, yang berarti bahwa penelitian ini tidak konsisten dengan teori Kotler (2005) yang menyatakan bahwa label halal merupakan salah satu faktor yang menjadi pertimbangan dalam proses keputusan pembelian konsumen. Hasil hipotesis ini juga bertentangan dengan hasil penelitian oleh Anggadwita, Dini dan Veland (2019), Ahidin (2019) dan Maulidiyah et al (2018) yang menyatakan label halal merupakan faktor dalam keputusan pembelian konsumen, namun 


\section{Paradigma: Jurnal Masalah Sosial, Politik, dan Kebijakan \\ http://jurnal.upnyk.ac.id/index.php/paradigma/index P-ISSN: 1410-3133. E-ISSN: Xxxx-xxxx}

hasil dari penelitian ini mendukung penelitian oleh Lutfie et al (2016) bahwa label halal tidak berpengaruh signifikan terhadap keputusan pembelian. Hal ini menunjukkan bahwa label halal yang tertera pada kemasan mi instan Samyang dapat meningkatkan image dari Samyang sebagai produk impor yang halal, namun tidak membuat konsumen melakukan pembelian.

\section{Pengaruh Kualitas Produk Terhadap Brand Image}

Berdasarkan hasil uji hipotesis 3, dapat dinyatakan bahwa kualitas produk berpengaruh signifikan terhadap brand image, yang berarti bahwa penelitian ini mendukung teori Parameswaran (2006) yang menyatakan bahwa produk dengan kualitas baik akan menghasilkan kepuasan dalam penggunaanya yang kemudian mempengaruhi perspektif konsumen pada brand image produk tersebut. Hasil hipotesis ini juga mendukung hasil penelitian oleh Anggadwita, Dini dan Veland (2019), Putra (2020) dan Kurnianto (2019) bahwa produk dengan kualitas yang baik dapat meningkatkan nilai pada brand image dari produk tersebut. Hal ini berarti bahwa kualitas produk mi instan Samyang dapat meningkatkan image dari Samyang sebagai produk yang berkualitas.

\section{Pengaruh Kualitas Produk Terhadap Keputusan Pembelian}

Berdasarkan hasil uji hipotesis 4, dapat diketahui bahwa keputusan pembelian mi instan Samyang oleh mahasiswa jurusan Ilmu Administrasi Bisnis UPN "Veteran" Yogyakarta dalam penelitian ini lebih dipengaruhi oleh kualitas produk daripada label halal pada kemasan. Hasil dari penelitian ini mendukung teori Kotler (2005) yang menyatakan bahwa konsumen hanya akan membeli produk dengan kualitas yang baik dan sesuai dengan kebutuhannya, serta temuan ini mendukung hasil penelitian oleh Lutfie et al (2016), Waluya (2019) dan Ginting (2017) bahwa kualitas produk merupakan faktor yang mempengaruhi keputusan pembelian konsumen. Hal ini berarti bahwa konsumen dalam penelitian ini, lebih memperhatikan kualitas produk daripada label halal yang tertera pada kemasan mi instan Samyang.

\section{Pengaruh Brand Image Terhadap Keputusan Pembelian}

Berdasarkan hasil uji hipotesis 5, dapat diketahui bahwa brand image memberikan pengaruh signifikan terhadap keputusan pembelian, sehingga dapat dinyatakan bahwa penelitian ini mendukung teori Parameswaran (2006) produk dengan brand image baik akan membuat konsumen membeli suatu produk meskipun dengan harga yang lebih tinggi serta mendukung hasil penelitian oleh Khairani (2018) dan Waluya (2019) bahwa produk yang memiliki Brand Image yang baik di benak pelanggan akan mempengaruhi pelanggan untuk melakukan keputusan pembelian. Hal ini menunjukkan bahwa Samyang memiliki brand image yang baik di benak konsumen sehingga dapat membuat konsumen tertarik untuk melakukan keputusan pembelian. 


\section{Paradigma: Jurnal Masalah Sosial, Politik, dan Kebijakan \\ http://jurnal.upnyk.ac.id/index.php/paradigma/index P-ISSN: 1410-3133. E-ISSN: Xxxx-xxxx}

Implikasi Hasil Penelitian:

Implikasi hasil penelitian bagi konsumen berupa meningkatnya kecermatan konsumen dalam mengambil keputusan pembelian, mencakup kualitas produk, kehalalan produk dan brand image produk

\section{Penutup}

Berdasarkan hasil dan analisis, dapat disimpulkan bahwa: label halal berpengaruh secara signifikan terhadap brand image, label halal tidak berpengaruh signifikan terhadap keputusan pembelian, kualitas produk berpengaruh secara signifikan terhadap brand image, kualitas produk berpengaruh secara signifikan terhadap keputusan pembelian dan brand image berpengaruh secara signifikan terhadap keputusan pembelian. Pada penelitian ini kualitas produk dan brand image lebih mempengaruhi keputusan pembelian konsumen daripada label halal, namun label halal pada kemasan produk dapat menambah nilai dari brand image produk begitu juga dengan kualitas produk. Implikasi penelitian ini bagi perusahaan adalah perlunya perencanaan produk secara terintegrasi, baik dari sisi kualitas produk, brand image, maupun kehalalannya.

Berdasarkan penelitian yang telah dilakukan, terdapat keterbatasan yang dialami dan dapat menjadi faktor yang lebih diperhatikan bagi peneliti-peneliti yang akan datang agar hasilnya lebih baik lagi. Adapun keterbatasan dalam penelitian ini terjadi karena kondisi pandemi yang menyebabkan peneliti hanya dapat menjangkau $15 \%$ dari seluruh mahasiswa yang ada sehingga hasil penelitian kurang maksimal.

\section{Daftar Pustaka}

Ahidin, Udin et al. 2019. Analysis of Decisions for Purchasing Imported Products in Mi Samyang through Halal Labels and Prices (Empirical Study in Indomaret Customers in the City of Bogor). International Journal of Innovative Science and Research Technology, Volume 4 Issue 10, 647-655.

Anggadwita, Grisna, Dini Turipanam Alamanda dan Veland Ramadani. 2019. Halal Label vs Product Quality in Halal Cosmetic Purchasing Decisions. IKONOMIKA: Jurnal Ekonomi dan Bisnis Islam, Volume 4 No. 2, 227 - 242.

Elliott, Richard H., Larry Percy dan Simon Pervan. 2015. Strategic Brand Management Third Edition.

UK:

Oxford

Press. https://books.google.co.id/books?id=KYUlCgAAQBAJ\&redir_esc=y. Diakses pada 18 November 2020.

Ghozali, Imam. 2014. Partial Least Squares: Konsep, Teknik dan Aplikasi Menggunakan Program SmartPLS 3.0. Semarang: Undip.

Ginting, Maretta dan Hendri Sembiring. 2017. The Effect of Product Innovation, Product Quality and City Image on Purchase Decision of Uis Karo Woven Fabric. Advances in Economics, Business and Management Research (AEBMR), Volume 46, 593-598. 


\section{Paradigma: Jurnal Masalah Sosial, Politik, dan Kebijakan \\ http://jurnal.upnyk.ac.id/index.php/paradigma/index P-ISSN: 1410-3133. E-ISSN: Xxxx-xxxx}

Hoyer, Wayne D. dan MacInnis, Deborah J. 2008. Consumer Behavior. USA: Cengage Learning. https://books.google.co.id/books?id=OwPwDwAAQBAJ\&source=gbs_navlinks_s. Diakses pada 28 November 2020.

https://books.google.co.id/books?id=skjMDwAAQBAJ\&dq=penelitian+eksplanatif\&so urce=gbs_navlinks_s. Diakses pada 28 November 2020.

Khairani. 2018. The effect of brand image and food safety on the purchase decision of samyang noodles product to the students of faculty of economics and business of university of north Sumatra medan. IJLRES - International Journal on Language, Research and Education Studies, Vol. 2 No. 2, 266 - 280.

Kotler, Philip dan Kevin Lane Keller. 2008. Manajemen Pemasaran Edisi 13 jilid 1. Penerbit Erlangga.

Kotler, Philip et al. 2005. Principles of Marketing Fourth European Edition. England: Pearson Education. Diunduh pada 12 November 2020.

Kurnianto, Wahyu Mega, Sylvia Sari Rosalina dan Nurminingsih. 2019. Effect of Marketing Mix and Product Quality on Purchase Decision to the Spesial Sb Packaging Beef Meatball through Brand Image and Purchase Intention. International Journal of Multicultural and Multireligious Understanding (IJMMU), Vol. 6 No. 2, 86-96.

Lppom-MUI. Pengertian Sertifikasi Halal MUI. http://lppommuibanten.org/?page=Statis\&id=8\#: :text=Sertifikat\%20Halal\%20MUI\%20adalah\%20 fatwa,dari\%20instansi\%20pemerintah\%20yang\%20berwenang. Diakses 12 September 2020.

Lutfie, Harie et al. 2016. Which is More Important? Halal Label or Product Quality. Atlantis Press.

Mahliza, Febrina. 2020. Consumer Trust in Online Purchase Decision. EPRA International Journal of Multidisciplinary Research (IJMR), Volume 6, Issue 2, 142-149.

Maulidiyah, Nailin Nikmatul et al. 2019. Customer Satisfaction as A Mediator The Impact of Halal Labeling on Cosmetic Purchasing Decision in Probolinggo. Global Science, 8894.

Parameswaran, M.G. 2006. Building Brand Value: Five Steps to Building Powerful Brands. New Delhi: Hill Publishing Company. https://books.google.co.id/books?id=fUEpjP6MNoC\&redir_esc=y. Diakses pada 18 November 2020.

Putra, Muhammad Thariq dan Adi Nurmahdi. 2020. Analysis of Effect Price and Quality on Brand image and its implication on purchase decision modena gas cooktop (case study on grand galaxy city residence Bekasi). Dinasti international journal of Digital Business Management, Volume 1 Issue 5, 747-761.

Simbolon, Freddy Pandapotan. 2019. The impact of halal label, price and brand on the purchase decision of bakso wagyu in kota wisata Cibubur. Journal The WINNERS, Vol. 20 No. 2, 111-120. 


\section{Paradigma: Jurnal Masalah Sosial, Politik, dan Kebijakan}

http://jurnal.upnyk.ac.id/index.php/paradigma/index P-ISSN: 1410-3133. E-ISSN: Xxxx-xxxx

Syahputra, Ady dan Haroni Doli Hamoraon. Pengaruh Labelisasi Halal terhadap keputusan Masyarakat Kecamatan Perbaungan dalam pembelian produk Makanan dalam kemasan. Jurnal Ekonomi dan Keuangan, Vol.2 No.8, 475-487. Diakses pada 12 November 2020.

Tjiptono, Fandy dan Anastasia Diana. 2019. Kepuasan Pelanggan: Konsep, Pengukuran \& Strategi. Yogyakarta: Penerbit Andi.

Tjiptono, Fandy. 2008. Strategi Pemasaran Edisi 3. Yogyakarta: Penerbit Andi.

Waluya, Aris Insan M., Ali Iqbal dan Rhian Indradewa. 2019. How product quality, brand image, and customer satisfaction affect the purchase decisions of Indonesian automotive customers. Int. J. Services, Economics and Management, Vol. 10 No. 2, 177-193.

WINA. 2020. Global Demand for Instant Noodles. https://instantnoodles.org/en/noodles/market.html diakses pada 12 November 2020.

Winarto, Jacinta. 2011. Hubungan antara Citra Merek dan Ekuitas Merek. Jurnal Manajemen, Vol. 10, No. 2, 103-114. 